\title{
Persistent Scattering Interferometry SAR based Velocity and Acceleration Analysis of Land Deformation: Case Study on Kelok Sembilan Bridge
}

\author{
Pakhrur Razi $^{1,2 *}$, Josaphat Tetuko Sri Sumantyo ${ }^{2 \ddagger}$, Daniele Perssin ${ }^{3 \S}$, Achmad Munir $^{4 \dagger}$ \\ ${ }^{1}$ Physics Department, Faculty of Mathematics and Natural Science, Universitas Negeri Padang, Indonesia \\ ${ }^{2}$ Josaphat Microwave Remote Sensing Laboratory, Center for Environmental Remote Sensing \\ Graduate School Advanced Integration Science, Chiba University, Japan \\ ${ }^{3}$ College of Engineering, Purdue University, West Lafayette, Indiana, USA \\ ${ }^{4}$ Radio Telecommunication and Microwave Laboratory \\ School of Electrical Engineering and Informatics, Institut Teknologi Bandung, Indonesia \\ *fhrrazi@fmipa.unp.ac.id, ${ }^{\ddagger}$ jtetukoss@ faculty.chiba-u.jp, ${ }^{\S}$ perissin@ purdue.edu, ${ }^{\dagger}$ munir@ieee.org
}

\begin{abstract}
Characteristic analysis of land deformation in some area is very helpful for mapping and preventing the impact of landslide. Here, Persistent Scatterer Interferometric (PSI) Synthetic Aperture Radar (SAR) technique has been applied on 13 scenes of ascending track acquired by Advanced Land Observation Satellite Phased Array L-band Synthetic Aperture Radar (ALOS PALSAR) from July 2007 until November 2010 for characteristic analysis of the landslide. The technique is employed to identify and measure land deformation on the earth surface. The PSI technique has good accuracy in overcoming temporal and geometric decorrelation compared to conventional interferometric SAR technique. The result for analyzing landslide deformed area on Kelok Sembilan bridge has been identified. In addition, time series of landslide deformation history were used for calculating the past velocity and acceleration of landslide as well as for estimating for the future.
\end{abstract}

Keywords-Acceleration; land deformation; Persistent Scatterer Interferometry (PSI); Synthetic Aperture Radar (SAR); velocity.

\section{INTRODUCTION}

The landslide frequently occurred in the Kelok Sembilan Bridge, Lima Puluh Kota district, West Sumatra, Indonesia is a motivation to analyse the characteristic of land movement. In recent years, there were around 50 landslide locations in the area of $44 \mathrm{~km}$ away from Payakumbuh through Kelok Sembilan to Pangkalan Koto Baru. The tragedy has been a remarkable geo-hazard in West Sumatra. In order to minimize the impact, characteristic analysis of velocity and acceleration of landslide is required. Basically, velocity and acceleration are physical quantities of object motion, therefore, they contribute to give early warning for humanity living inside the area.

One of techniques mostly applied to analyze the characteristic of landslide through its velocity and acceleration is Persistent Scatterer Interferometry (PSI) Synthetic Aperture Radar (SAR). The technique has very high credibility in the implementation especially for disaster monitoring. The PSI technique is the advanced of traditional interferometry technique resolving the limitation in geometric and temporal decorrelation [1]-[2], as well as for atmospheric disturbance problem [3]. The technique has also capability to produce high accuracy result up to millimeters order [4]-[5].
In this paper, the research is proposed to analyze the characteristic of velocity and acceleration of landslide in monitoring the land deformation to be correlated with the rainfall intensity. The focused area for the analysis is taken at Kelok Sembilan Lima Puluh Kota district, West Sumatra, Indonesia. The result of analysis can be then used for a consideration in land mapping and landslide prediction in the future.

\section{Area of Study And Methods}

Historically, Kelok Sembilan road was built during the reign of Dutch East Indies. The area of study is located at latitude of $0^{\circ} 4$ ' $13.30^{\prime \prime} \mathrm{S}$ and longitude of $100^{\circ} 41^{\prime} 53.56^{\prime \prime} \mathrm{E}$ Limapuluh Kota District, West Sumatra, Indonesia as shown in Fig. 1. The road is situated in the slope of hill, less wide,

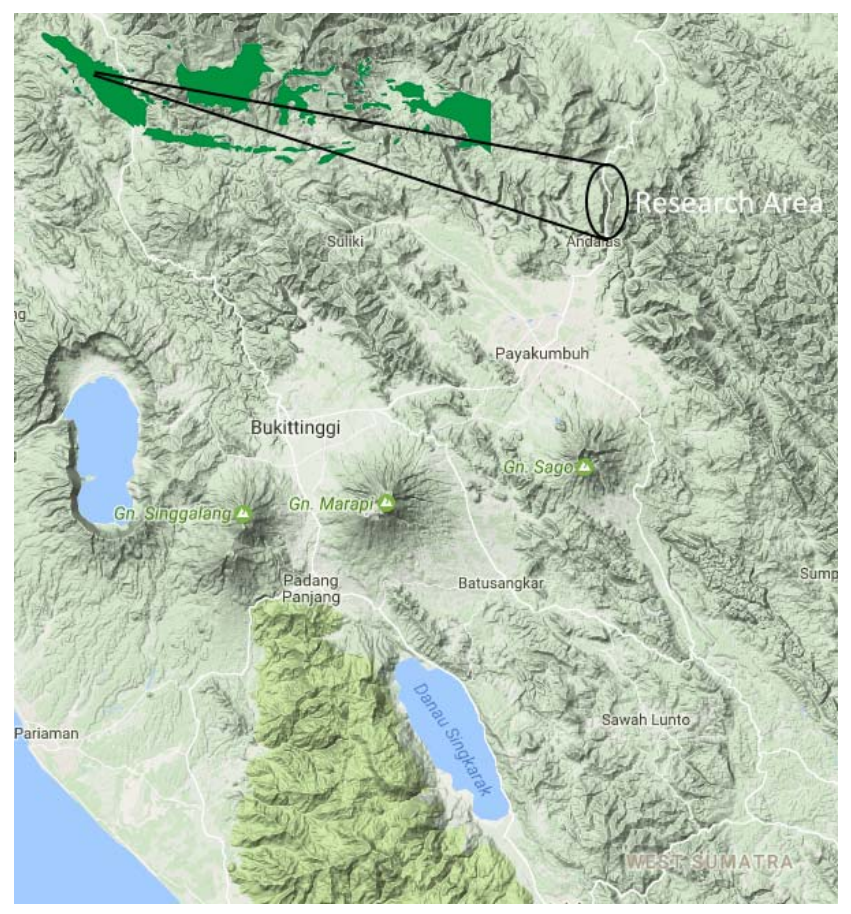

Fig. 1. Area of study in Kelok Sembilan West Sumatra, Indonesia. 
winding, and steep, in which the traffic jam almost occurred. The area was also not infrequently attached by landslides. For monitoring the land deformation activity, 13 scenes of ALOS PALSAR was employed. The data acquisition was taken from July 2007 to November 2010. The type of SAR data is Fine Double Beam (FDB) mode (HH, HV) and ascending track. Whilst, revisited time for ALOS PALSAR satellite is 46 days.

Processing mechanism of ALOS PALSAR data on the research area is employed by PSI technique. The technique utilizes the difference phase individual observation for each data acquisition to detect the land deformation. The interferometric phase signal received by satellite antenna contains a contribution of earth curvature, elevation, displacement, atmospheric and noise. Moreover, the technique also considers the strong and consistent backscatter in time [1].

Theoretically, the average displacement velocity of deformation along line of sight (LOS) is expressed in (1) [6].

$$
v_{d i s p}=\left(\lambda \cdot \phi_{j}\right) /\left(4 \pi \cdot t_{j}\right)
$$

where $v_{d i s p}$ is the velocity of displacement (in $\mathrm{mm} /$ month), $a_{d i s p}$ is acceleration of deformation (in $m m /\left(m o n t h^{2}\right)$ ), $\lambda$ is the wavelength (in $m m$ ), $\phi_{j}$ is unwrapped phase, and $\mathrm{t}_{j}$ is acquisition time interval (in month). Meanwhile the acceleration of deformation for each acquisition is derived from the physical law of motion given in (2),

$$
a_{d i s p}=\frac{v_{d i s p}}{t_{j}}
$$

The deformation value of PSI processing is produced by calculating the difference value between two revisited times. The time acquisition is obtained from ALOS PALSAR data set. It is noted that the velocity and acceleration of land deformation are physical vector quantities and have magnitude as well as direction. While the direction is marked by negative and positive symbols in which the negative symbol means the land is moving far away from LOS of satellite and the negative symbol means the land is coming up to LOS of satellite.

\section{RESUlt AND Discussion}

In this study, there are 13 scenes of ascending track acquired by ALOS PALSAR from July 2007 to November 2010. The maximum perpendicular baseline is set to be 758 $\mathrm{m}$ for acquisition on July 8, 2009 and the minimum one is on August 18, 2008. The combinations of maximum and minimum perpendicular baseline are suitable for coherency and terrain accuracy. The time acquisition on October 5, 2008 is chosen as a master data according to optimization perpendicular and temporal baseline and atmosphere condition [1], [3]. The network distribution is shown in Fig. 2. Meanwhile, the distribution of Persistent Scatter (PS) point is shown in Fig. 3. The time series deformation processed by PSI in two areas of the landslide, i.e. area 1 and area 2, are represented by point ID 626 and ID 1058. The trend deformation graph for area 1 and area 2 are plotted in Figs. 4 and 5, respectively, in which both are linear with negative direction far away from LOS of satellite, although some of them are shifted to positive direction to LOS of satellite.

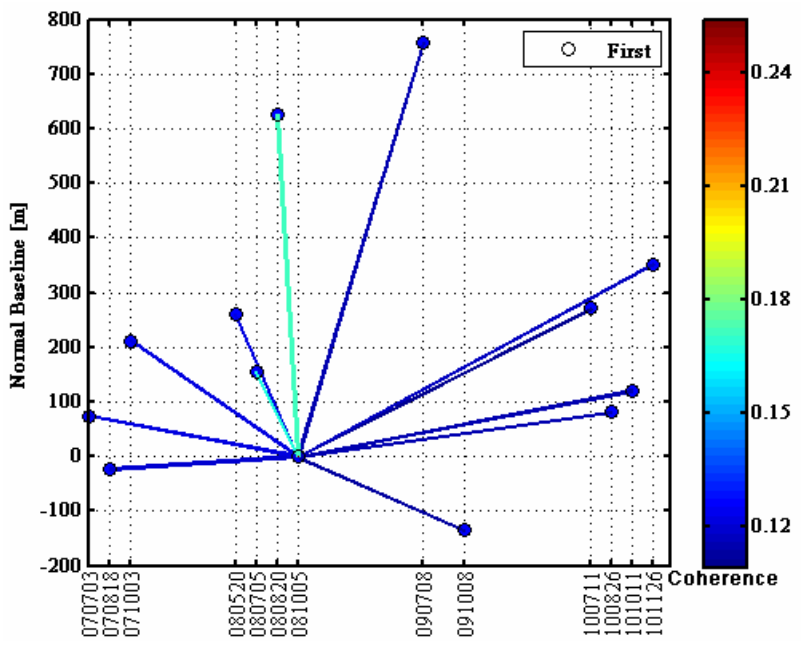

Fig. 2. Normal and temporal baseline network.

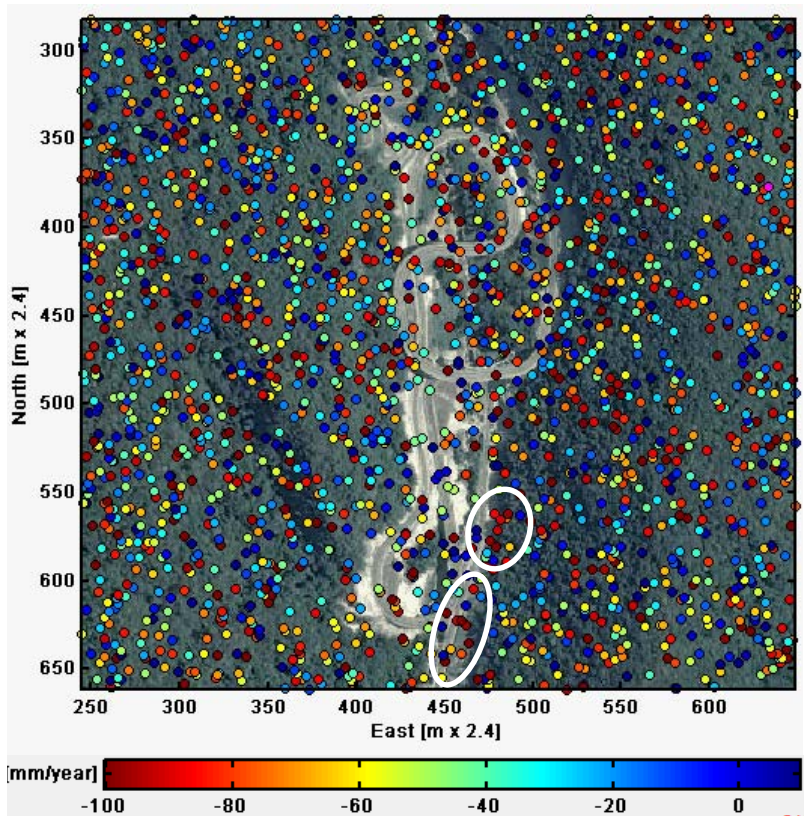

Fig. 3. PS point distribution on Kelok Sembilan area.

The negative one means that the subsidence occurred and the positive one is an uplift on the area. The cumulative deformation represented by ID 626 and ID 1058 is $-347.4 \mathrm{~mm}$ and $-234.5 \mathrm{~mm}$, respectively. The coherency of both points is 0.73 . The maximum and minimum velocity for ID 626 acquired between August 20, 2008 to October 5, 2008 and July 11, 2010 to August 26, 2010 is $-28.1 \mathrm{~mm} / \mathrm{month}$ and 3.1 $\mathrm{mm} / \mathrm{month}$, respectively. Although $\Delta$ Def. at acquisition time on October 8, 2009 to July 11, 2010 is higher $(-92.7 \mathrm{~mm})$ than of August 20, 2008 to October 5, 2008 ( $-43.0 \mathrm{~mm})$, however the acquisition time on October 8, 2009 to July 11, 2010 is the longest one (see Table I).

The data acquired on August 8, 2007 to October 2, 2007 has the maximum velocity for ID 1058 of $-40.7 \mathrm{~mm} / \mathrm{month}$, while the minimum one is $-2.4 \mathrm{~mm} / \mathrm{month}$ for the acquisition time on Augustus 20, 2008 to October 5, 2008. Acceleration 
TABLE I. VELOCITY AND ACCELERATION OF LAND DEFORMATION ON KELOK SEMBILAN.

\begin{tabular}{|c|c|c|c|c|c|c|c|c|c|}
\hline \multirow{2}{*}{$\begin{array}{c}\text { Time Acquisition } \\
\text { (dd·mm·yyyy) }\end{array}$} & \multicolumn{4}{|c|}{ 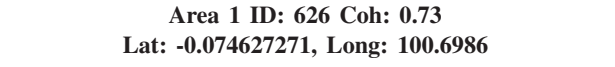 } & \multicolumn{4}{|c|}{$\begin{array}{c}\text { Area } 2 \text { ID: } 1058 \text { Coh: } 0.73 \\
\text { Lat: }-0.07339 \text {, Long: } 100.69913\end{array}$} & \multirow{2}{*}{$\begin{array}{c}\text { Rainfall Intensity } \\
\text { (mm) }\end{array}$} \\
\hline & $\begin{array}{l}\text { Time series Def. } \\
(\mathrm{mm})\end{array}$ & $\begin{array}{l}\Delta \text { Def. } \\
(\mathrm{mm})\end{array}$ & $\begin{array}{c}\text { Velocity } \\
\text { (mm/month) }\end{array}$ & $\begin{array}{l}\text { Acceleration } \\
\left(\mathrm{mm} / \text { month }^{2}\right)\end{array}$ & $\begin{array}{c}\text { Time series Def. } \\
(\mathrm{mm})\end{array}$ & $\begin{array}{c}\Delta \text { Def. } \\
(\mathrm{mm})\end{array}$ & $\begin{array}{c}\text { Velocity } \\
(\mathrm{mm} / \text { month })\end{array}$ & $\begin{array}{l}\text { Acceleration } \\
\left(\mathrm{mm} / \text { month }^{2}\right)\end{array}$ & \\
\hline $\begin{array}{c}03072007 \text { to } \\
18082007\end{array}$ & -36.3 & 36.3 & -23.7 & -15.5 & 20.2 & 20.2 & 13.2 & 8.6 & 225 \\
\hline $\begin{array}{l}18082007 \text { to } \\
03102007\end{array}$ & -70.6 & -34.3 & -22.4 & -14.7 & -42 & -62.2 & -40.7 & -26.6 & 225.5 \\
\hline $\begin{array}{l}03102007 \text { to } \\
20052008\end{array}$ & -112.1 & -41.5 & -5.5 & -0.7 & -30.9 & 11.1 & 1.5 & 0.2 & 328.6 \\
\hline $\begin{array}{c}20052008 \text { to } \\
05072008\end{array}$ & -137.2 & -25.1 & -16.4 & -10.7 & -46.4 & -15.5 & -10.1 & -6.6 & 184 \\
\hline $\begin{array}{l}05072008 \text { to } \\
20082008\end{array}$ & -104.3 & 32.9 & 21.5 & 14.1 & -71.9 & -25.5 & -16.7 & -10.9 & 224.5 \\
\hline $\begin{array}{c}20082008 \text { to } \\
05102008\end{array}$ & -147.3 & -43.0 & -28.1 & -18.4 & -75.6 & -3.7 & -2.4 & -1.6 & 287.5 \\
\hline $\begin{array}{l}05102008 \text { to } \\
08072008\end{array}$ & -228.6 & -81.3 & -8.8 & -1.0 & -128.2 & -52.6 & -5.7 & -0.6 & 234.2 \\
\hline $\begin{array}{l}05102008 \text { to } \\
08072009\end{array}$ & -228.6 & -81.3 & -8.8 & -1.0 & -128.2 & -52.6 & -5.7 & -0.6 & 234.2 \\
\hline $\begin{array}{l}08072009 \text { to } \\
08102009\end{array}$ & -240.7 & -12.1 & -4.0 & -1.3 & -146.4 & -18.2 & -5.9 & -1.9 & 187 \\
\hline $\begin{array}{c}08102009 \text { to } \\
11072010\end{array}$ & -333.4 & -92.7 & -10.1 & -1.1 & -189.5 & -43.1 & -4.7 & -0.5 & 343.8 \\
\hline $\begin{array}{l}11072010 \text { to } \\
26082010\end{array}$ & -328.6 & 4.8 & 3.1 & 2.1 & -231.2 & -41.7 & -27.3 & -17.8 & 346 \\
\hline $\begin{array}{l}26082010 \text { to } \\
11102010\end{array}$ & -361.9 & -33.3 & -21.8 & -14.2 & -230.3 & -0.9 & 0.6 & 0.4 & 333.3 \\
\hline $\begin{array}{l}11102010 \text { to } \\
26112010\end{array}$ & -347.4 & 14.5 & 9.5 & 6.2 & -234.5 & -4.2 & -2.7 & -1.8 & 314.5 \\
\hline
\end{tabular}

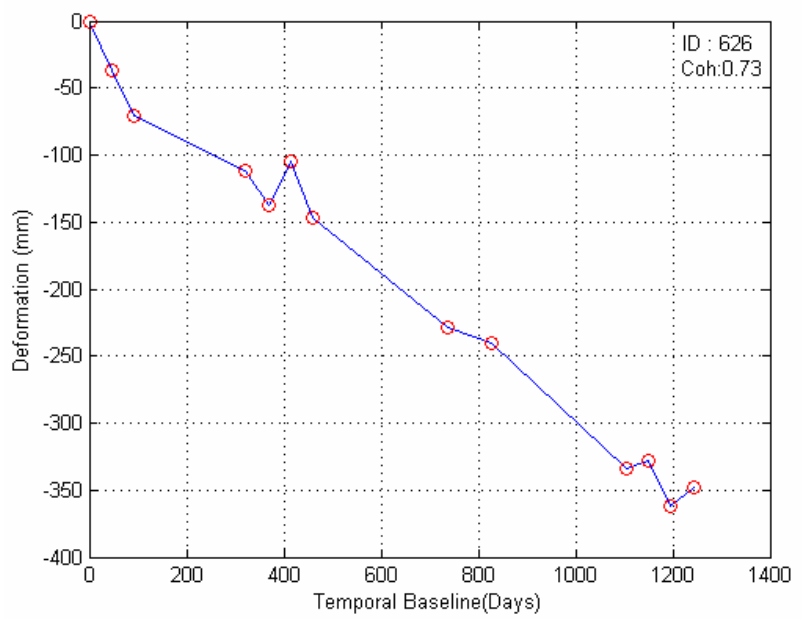

Fig. 4. Trend deformation graph for area 1 (ID: 626).

analysis is required for confirming the factor of land velocity changing. Here, the acceleration of land deformation is then correlated with the rainfall intensity. The acceleration graph for both areas, e.g. ID: 656 and ID: 1058, are depicted in Figs. 6 and 7 , respectively. The horizontal axis is temporal baseline (in day) and the vertical one is cumulative acceleration (in $\mathrm{m} / \mathrm{s}^{2}$ ). The acceleration magnitude and direction for each revisited time ALOS PALSAR are shown in value and color on the graph, respectively. The yellow color represents the negative acceleration where the land moves far away from LOS of satellite, while the blue one is the positive acceleration where the land comes up to LOS of satellite.

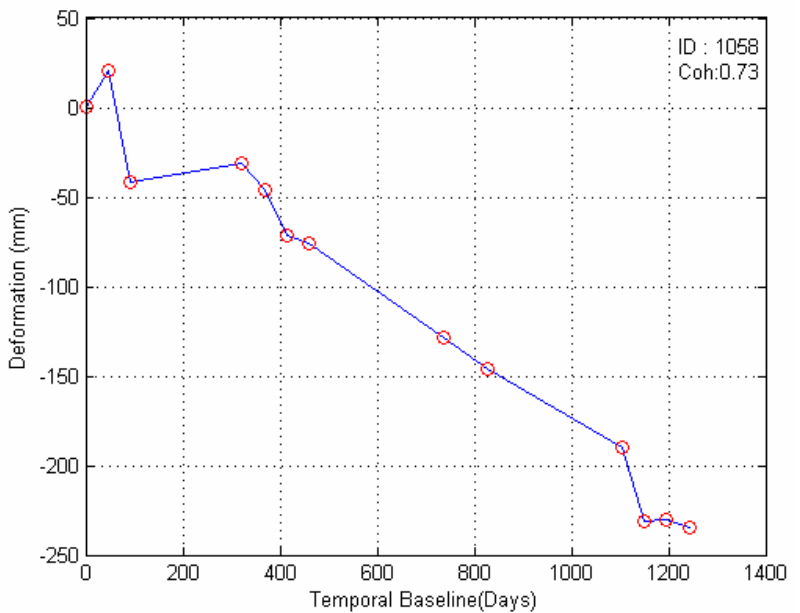

Fig. 5. Trend deformation graph for area 2 (ID: 1058).

Fig. 8 shows the rainfall intensity on the area of study in which the intensity of around $287.5 \mathrm{~mm}$ is categorized into medium rainfall intensity. At the first point of interest represented by ID 626 (area 1), the maximum acceleration is $-18.4 \mathrm{~mm} / \mathrm{month}^{2}$ occurred on August 20, 2008 - October 5, 2008. Furthermore, for the second point of interest represented by ID 1058 (area 2), the acquisition time taken on August 18, 2007 to October 03, 2007 and July 11, 2010 to August 26, 2010 is the first and second highest acceleration, about $26.6 \mathrm{~mm} / \mathrm{month}^{2}$ and $-17.8 \mathrm{~mm} / \mathrm{month}^{2}$, respectively. In this interval time the rainfall intensity is classified into medium and high rainfall intensities [7]. 


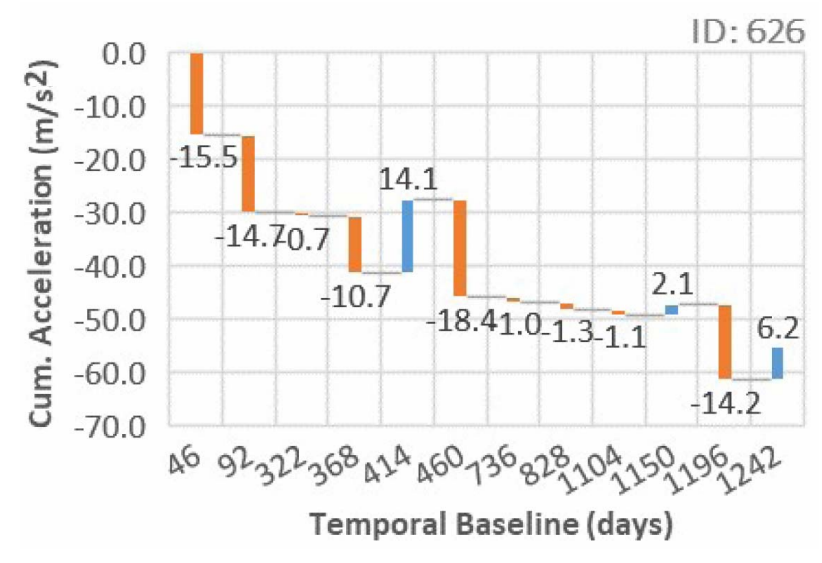

Fig. 6. Acceleration graph for area 1 (ID: 626).

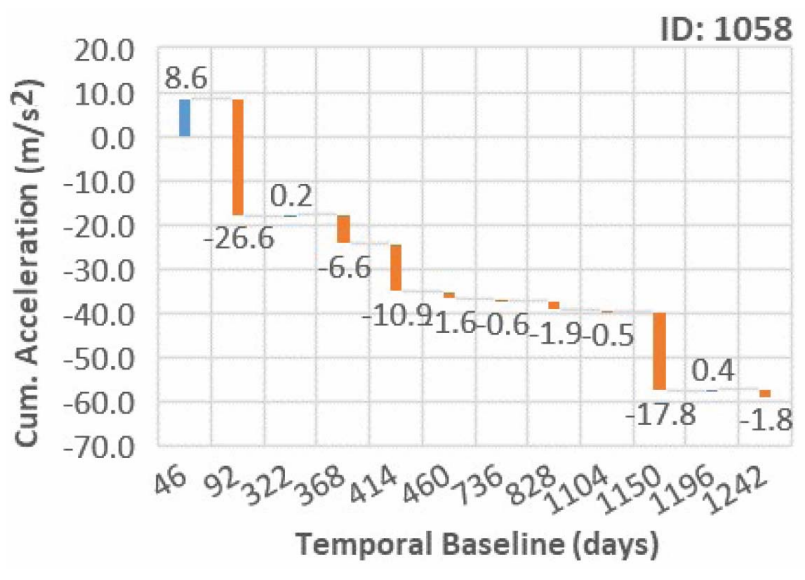

Fig. 7. Acceleration graph for area 2 (ID: 1058).

\section{CONCLUSION}

The PSI technique has been successfully implemented to analyze the land deformation with case study at Kelok Sembilan Lima Puluh Kota district, West Sumatra, Indonesia. The velocity and acceleration of landslide for each time acquisition were the average value revisit between times. The relation between velocity, acceleration and rainfall intensity has strong correlation each other. It has been shown that when the velocity and acceleration of landslide was high, the rainfall intensity was also high, and vice versa. In addition, the method of changing detection is currently being implemented to verify the condition of study area.

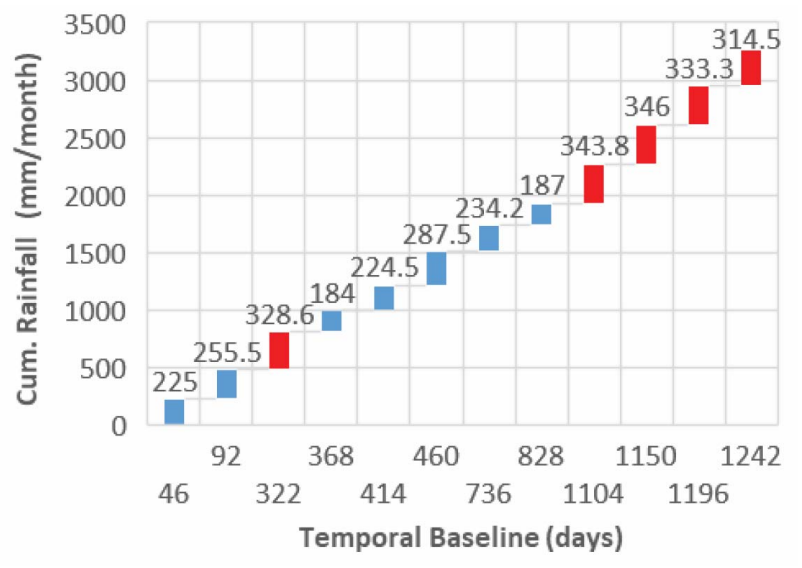

Fig. 8. Rainfall intensity on area of study.

\section{ACKNOWLEDGMENT}

The authors wish to thank Chiba University for the Scholarship, Japan Aerospace Exploration Agency (JAXA) for ALOS PALSAR data, and SARPROZ for providing processing tool for data.

\section{REFERENCES}

[1] A. Ferretti, C. Prati, and F. Rocca, "Nonlinear subsidence rate estimation using permanent scatterers in differential SAR interferometry," IEEE Trans. Geosci. Remote Sens., Vol. 38, No. 5, pp. 2202-2212, Sep. 2000.

[2] A. Ferretti, C. Prati, and F. Rocca, "Permanent scatterers in SAR interferometry," in Proceedings of IEEE International Geoscience and Remote Sensing Symposium (IGARSS), Hamburg, Germany, Jun.-Jul. 1999, pp. 1528-1530.

[3] B. M. Kampes, Radar Interferometry: Persistent Scatterer Technique, Springer, 2006.

[4] D. Perissin, "Validation of the submetric accuracy of vertical positioning of PSs in C-band," IEEE Geosci. Remote Sens. Lett., Vol. 5, No. 3, pp. 502-506, Jul. 2008.

[5] J. T. Sri Sumantyo, B. Setiadi, D. Perissin, S. Masanobu, P. P. Mathieu, and M. Urai, "Analysis of land deformation velocity using PSI ALOS PALSAR: Impact of coastal sedimentation to future Jakarta giant sea wall and waterfront city," in Proceedings of IEEE $5^{\text {th }}$ Asia-Pacific Conference on Synthetic Aperture Radar (APSAR), Singapore, Sep. 2015, pp. 516-521.

[6] T. Strozzi, U. Wegmiiller, C. Werner, and A. Wiesmann, "Measurement of slow uniform surface displacement with mm/year accuracy,"in Proceedings of IEEE International Geoscience and Remote Sensing Symposium (IGARSS), Honolulu, USA, Jun. 2000, pp. 2239-2241.

[7] BMKG, "Rainfall Intensity," 2007-2010. [Online]. Available: http://dataonline.bmkg.go.id/mcstation_metadata. 